\title{
Household routines: identifying contextual cues for energy related activities
}

\author{
Mary Barreto \\ Madeira Interactive Technologies Institute (M-ITI) \\ University of Madeira \\ Funchal, Portugal \\ mary.barreto@m-iti.org \\ Index Terms - home routines, energy, and contextual cues.
}

\section{INTRODUCTION AND MOTIVATION}

Technology has become embedded in how people conduct their daily lives within their home space [1]. A number of studies suggest changing context cues, which trigger existing or habitual behaviors [2] [3]. People's habits have been studied for a long time in terms of health, work productivity and sustainability [3] [4] [5]. A closer look to habits suggests these contain important elements for analyzing repetitive routines [3] [2] [6]. According to [7] habits are a complex structure that work in the format of a loop composed by cues, routines and rewards. Cues trigger routines, a group or a set of behaviors, people engage in to achieve particular rewards. As a consequence, people develop some kind of craving associated to these, therefore becoming a repetitive behavior and ultimately, a habit. The challenge to intervene in such loop is the fact that cues are difficult to read within the diversity of aspects behaviors are emerged in.

If practices are more of a response to routines [2] [8] [9] [10] rather than saving and being ecofriendly, in order to modify behaviors, interventions and smart systems would need to be designed specifically to target habits. More specifically, being routines part of behaviors and prompted by contextual cues, these could further inform how behaviors work. In this case, uncover the rewards behind the repetitive consumption behaviors. Inspired by the habit loop structure [7], this work aims to identify contextual cues that trigger household routines or behaviors

\section{METHOD}

A questionnaire was prepared to elicit the following information: which and what types of cues are present in household routines? The questionnaire was designed to collect cues for five home routines (designated it as activities): cooking or preparing a meal, cleaning, entertainment, laundry and personal care. For each activity, six questions were created based on specific elements: location (Where were you?), time (What time was it?), emotional state (What was your emotional state?), other people (Who else was around?), immediately preceding action (What did you do before this activity?) and technology (Did you use any electronic device? Which one (s)?). These were driven from the loop habit structure [7] and are used to help identify cues within the five activities, which were selected due to their potential technology and energy use. Users instead of being suggested by the researcher provided the cues.

The questionnaire was translated into three languages (English, Portuguese and Spanish) and pre-tested for language accuracy to achieve a more representative sample of activities and cues. Participants were recruited using a snowball sample methodology, through email solicitations in online groups to social media websites. These solicitations were sent at the end of the working day to gather as much information, since early morning would only capture part of the day activities.

In total 95 participants completed the questionnaire (across a span of 7 days) and were distributed across 16 countries. The sample was in its majority female (64 out of 95), with an average age of 32.5 years old $(\mathrm{SD}=7.2)$, and mostly families with one child (16 out of 95) or just couples (71 out of 95). In terms of household size, 65 participants were below 3 people per unit. All open-ended responses were coded iteratively using a grounded-theory approach to qualitative analysis where for each cue element, similar provided answers were merged into higher-level categories [11].

\section{RESULTS}

The most frequent activities reported were personal care and entertainment taking place several times a day. The least frequent ones were laundry and cleaning being conducted once a week (see fig. 1). For each activity most frequent cues (the three to four most referred to) were gathered to demonstrate each one in detail (see Table I). In terms of location, all activities were linked to specific household sites directly connected to the nature of the activity. For time the activities would take place early morning (6 to $9 \mathrm{am}$ ) or early evening (6 to $8 \mathrm{pm}$ ). Emotional state was diverse for overall activities, where reports of feeling tired and happy came across all activities. Referring to other people while conducting an activity, these would either be conducted alone or have the presence of a partner or spouse. Preparing or having a meal was a common preceding action among cleaning, entertainment, laundry and personal care. Coming home from work was a common preceding action for cooking, cleaning and entertainment. Electronic devices were specific for each activity and directly connected to its goals. For instance, personal care most frequent 
devices were electronic toothbrush, water heater and hair dryer or even none (for example, the action of getting dressed).

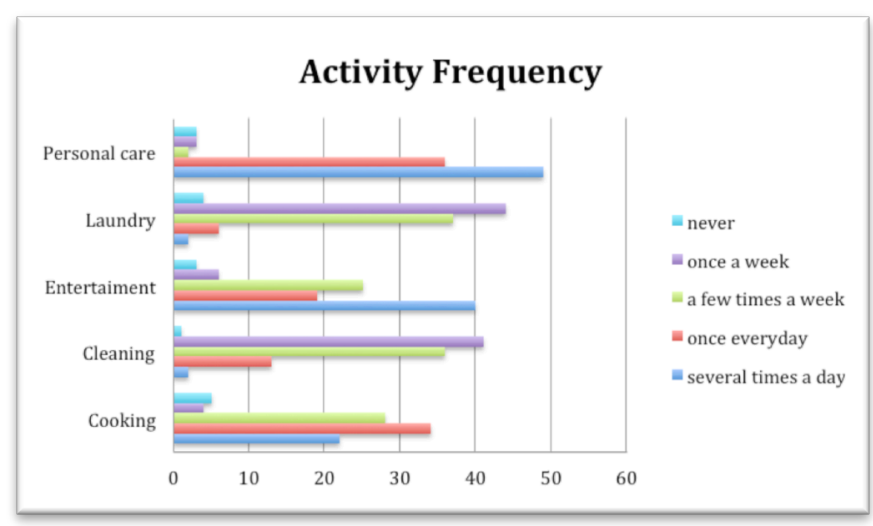

Fig. 1. Activity frequency.

\section{DISCUSSION AND CONCLUSIONS}

This work collected a sample of user given cues for five home activities. For each one it was possible to list specific information around six questions to help uncover cues associated with each activity or home routine. Regarding these, common cues were found across activities. For instance, preparing or having a meal was associated as a preceding action for the other four activities, suggesting there might be a close connection between activities across the day, either as automatic responses or even as bridges participants regularly use to achieve their daily goals. Furthermore, emotional state where tired, happy and relaxed emerged, were dependent on specific time frames, either early morning (lighter feelings) or early evening (tiredness). This seems to suggest activities might be conducted to diminish such emotional states, in detriment of making the best and most efficient decisions. This seems to reinforce that smart and sustainable systems need to be grounded in how people conduct their home activities [9] [10]. Finding about the cues that trigger behaviors allows for a higher success rate in terms of changing habits, as you might be able to make people crave for specific rewards. Finding out which cravings and rewards might be relevant for these energy driven activities seems important for the future design of smart and sustainable systems. Smart because these will anticipate and be responsive to users needs/cravings, and sustainable, by potentially replacing unsustainable for more sustainable practices that provide equivalent rewards, and therefore most likely, be repeated and adopted within the household.

The current research contains some limitations that future work could address such as expanding the sample of respondents, to reach larger households with children and older participants, since the current very young sample might be a result of using mostly social media to disseminate the survey. Use the current list of cues, which is far more extensive than the summary provided to create a larger database, and probe for more routines and cues. And ultimately generate an activity map where cues, routines and rewards can be linked to real user practices.
TABLE I. Example of three activities cue analysis.

\begin{tabular}{|c|c|c|c|}
\hline \multirow{2}{*}{ Cues } & \multicolumn{3}{|c|}{ Activities } \\
\hline & Cooking & Clean & Entertainment \\
\hline Location & $\begin{array}{l}\text { Kitchen } \\
\text { Dinning room }\end{array}$ & Kitchen & $\begin{array}{l}\text { Living room } \\
\text { Bedroom } \\
\text { Kitchen }\end{array}$ \\
\hline Time & $\begin{array}{l}7-8 \mathrm{am} \\
7-8 \mathrm{pm}\end{array}$ & $\begin{array}{l}8 \mathrm{am} \\
6-8 \mathrm{pm}\end{array}$ & $\begin{array}{l}6-7 \mathrm{pm} \\
9-11 \mathrm{pm} \\
\text { Most of the day }\end{array}$ \\
\hline $\begin{array}{l}\text { Emotional } \\
\text { State }\end{array}$ & $\begin{array}{l}\text { Tired } \\
\text { Contentment } \\
\text { Normal }\end{array}$ & $\begin{array}{l}\text { Tired } \\
\text { Happy }\end{array}$ & $\begin{array}{l}\text { Relaxed } \\
\text { Happy } \\
\text { Tired }\end{array}$ \\
\hline Other People & $\begin{array}{l}\text { Alone } \\
\text { Partner/spouse }\end{array}$ & $\begin{array}{l}\text { Alone } \\
\text { Partner/spouse }\end{array}$ & $\begin{array}{l}\text { Alone } \\
\text { Partner/spouse }\end{array}$ \\
\hline $\begin{array}{l}\text { Preceding } \\
\text { action }\end{array}$ & $\begin{array}{l}\text { Came in from } \\
\text { work }\end{array}$ & $\begin{array}{l}\text { Eat (Meal) } \\
\text { Came in from } \\
\text { work }\end{array}$ & $\begin{array}{l}\text { Eat/have } \\
\text { breakfast (Meal) } \\
\text { Prepare a meal } \\
\text { Work }\end{array}$ \\
\hline Device & $\begin{array}{l}\text { None } \\
\text { Microwave } \\
\text { Kettle }\end{array}$ & $\begin{array}{l}\text { None } \\
\text { Vacuum }\end{array}$ & $\begin{array}{l}\text { Tv } \\
\text { Mobile } \\
\text { (news/music/bro } \\
\text { wse the internet) } \\
\text { Laptop } \\
\text { (Music/news) }\end{array}$ \\
\hline
\end{tabular}

\section{REFERENCES}

[1] A. Desjardins, R. Wakkary, and W. Odom, "Investigating Genres and Perspectives in HCI Research on the Home," in Proceedings of the 33rd Annual ACM Conference on Human Factors in Computing Systems, New York, NY, USA, 2015, pp. 3073-3082.

[2] B. Verplanken, "Beyond frequency: Habit as mental construct," Br. J. Soc. Psychol., vol. 45, no. 3, pp. 639-656, 2006.

[3] D. T. Neal, W. Wood, J. S. Labrecque, and P. Lally, "How do habits guide behavior? Perceived and actual triggers of habits in daily life," J. Exp. Soc. Psychol., vol. 48, no. 2, pp. $492-$ 498, 2012.

[4] C. Katzeff and J. Wangel, "Social Practices, Households, and Design in the Smart Grid," in ICT Innovations for Sustainability, vol. 310, L. M. Hilty and B. Aebischer, Eds. Springer International Publishing, 2015, pp. 351-365.

[5] Dan Lockton, Flora Bowden, Catherine Greene, Clare Brass, and Rama Gheerawo, "People and energy: A design-led approach to understanding everyday energy use behaviour," presented at the EPIC Board of Directors, 2013.

[6] B. Verplanken and W. Wood, "Interventions to Break and Create Consumer Habits," J. Public Policy Mark., vol. 25, no. 1, pp. 90-103, 2006.

[7] Charles Duhigg, The Power of Habit: Why we do what we do and how to change. William Heinemann, 2012.

[8] M. L. Barreto, A. Szóstek, E. Karapanos, N. J. Nunes, L. Pereira, and F. Quintal, "Understanding families' motivations for sustainable behaviors," Comput. Hum. Behav., vol. 40, pp. $6-15,2014$.

[9] Y. A. A. Strengers, "Designing Eco-feedback Systems for Everyday Life," in Proceedings of the SIGCHI Conference on Human Factors in Computing Systems, New York, NY, USA, 2011, pp. 2135-2144.

[10] T. Schwartz, G. Stevens, L. Ramirez, and V. Wulf, "Uncovering Practices of Making Energy Consumption Accountable: A Phenomenological Inquiry," ACM Trans Comput-Hum Interact, vol. 20, no. 2, pp. 12:1-12:30, May 2013.

[11] A. Strauss and J. Corbin, "Grounded theory methodology," Handb. Qual. Res., pp. 273-285, 1994. 